\title{
不動点定理を用いたある最適制御問題の 数值計算法
}

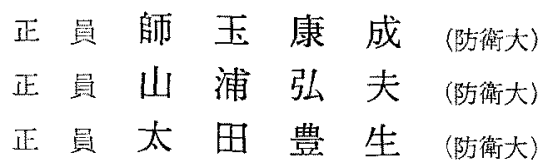

\section{1. まえがき}

非線形最道制御閵题の数値計算法のう方, 間題を变 分法などにより常微分方程式の 2 点境界值問題に婦着 させて解く方法では，その非線形方程式を变分方程式 や,ベルマンの準線形化法などによって準線形化し， 線形方程式の境界值問題解法の理論䎞適用することが 上〈行わ机ている(1)-(3)。乙れらばニュートン・ラプ ソン法を基整に和いている。この方法は最初に与える 推定解加，解の十分近くに与えられた場合二次収束 し，高い精度の数值解加得られる。

しかし，をうでないときには計算の過程で過大な修 正量が発生し，オーバフローのためにそのままでは計 算が継続できなくなることが多い。うのため，過大な 修正量を挪制するためにいるいるな工夫がなされてい

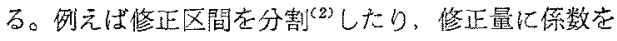
か於たりする゙る。

そ机らの土夫学ほどししてあ，そのアルゴリズムの 局所的な 2 次収束性が証明されているものもあるの で，収束の速さや解の精度の点では有效なものである 加，アルゴリズム自体が非常に複墔になるため，シス テムの次数が高くなったりすると，その寒行が難加し くなるむのが多い。

また，最初に与える推定解屯未知なので，解の近く に与光るのは難かしい。奏際の数值計算ではこれらの 収束の速い方法之，むしろ解の精度や収束の速さを 熾牲にしても，計算の過程でオーバフローが発生しに くくアルゴリズムが簡単であり，近似解を容易汇得る

Computation Method of a Optimal Control Problem using Fixed Point Theorem. By Yasunari Shidama, Member, Hiroo Yamaura, Member \& Toyomi Ohta, Member (Department of Electrical Engineering, The National Defense Academy).

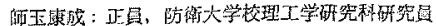

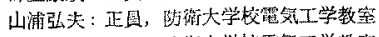

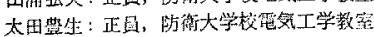

ことができる方法を併用することが必要亡考えられ る。

本研究では，その一つの方法として不勳点定理を用 いて, ニュートン法化よらずに近似解们漸近的に双束 するアルゴリズムを考案した。

\section{記㕺法}

関数 $h_{m}(x, y)$ D $x, y$ に関する偏徽分を

$$
\begin{aligned}
& \frac{\partial}{\partial x} h_{m}(x, y) \triangleq h_{z^{m}} \\
& \frac{\partial^{2}}{\partial x \partial y} h_{m}(x, y) \triangleq h_{x, y^{m}} \\
& \text { のうに表す。xが } n \text { 次元ベクトル } \\
& x=\left[x_{1}, \cdots, x_{n}\right]^{T}
\end{aligned}
$$

であるとき〔 $T$ は転圆記号を示す〕，関数 $g(x)$ の $x$ 飞関する偏微分 $g_{x}$ を次の $n$ 次元行ベクトルとして 定義する。

$$
g_{x} \triangleq\left(g_{x 1}, \cdots, g_{x n}\right)
$$

屯し $g(x)$ が $n$ 次元行ベ多ルならば $g x$ は

$$
g_{x}=\left[\begin{array}{l}
g_{x 1^{1} \cdots g_{x n}{ }^{1}} \\
g_{x 1^{n} \cdots g_{x n^{n}}}
\end{array}\right]
$$

のよう比表現される。また，表現考簡単化するため， $\left\langle g_{x}\right\}^{T}$ を $g_{x}^{T}$ で表す。

\section{2. 問題の定式化}

制御対象の状態力程式および初期条件がえ机を゙れ，

$$
\begin{aligned}
& \dot{x}(t)=A(t) x(t)+B(t) u(t)+g(x(t)) \\
& x\left(t_{i}\right)=x_{i} \ldots \ldots \ldots \ldots \ldots \ldots \ldots \ldots \ldots \ldots \ldots \ldots \ldots \ldots \ldots \ldots \ldots \ldots \ldots \ldots
\end{aligned}
$$

で与光られ，最小儿する評佂関数 $J(u)$ が

$$
\begin{aligned}
J(u)= & \int_{t_{i}}^{t_{f}}\left\{\frac{1}{2} x^{T}(t) Q(t) x(t)+\frac{1}{2} u^{T}(t) R(t) u(t)\right. \\
& +q(x(t))\} d t+\frac{1}{2} x^{T}\left(t_{f}\right) Q_{f} x\left(t_{s}\right)
\end{aligned}
$$


である埸合の最適制御閴題を考える。

ここに，t時間変数で制御区間は $\left(t_{i}, t_{f}\right)$ とする。 また， $A(t), B(t), Q(t), R(t)$ はそれぞれ $n \times n, n \times$ $m, n \times n, m \times m$ の㭙変形の定数行列で， $Q(t)$ は対称 準正定， $R(t)$ は対称正定であり，Q，估 $n \times n$ の定数 行列, $g(x(t)) \in R^{a}$ は $n$ 次べクトル, $q(x(t))$ はスカラ とする。 $x(t) \in R^{n}, u(t) \in R^{m}(m \leqslant n)$ は, 時刻 $t \in\left[t_{i}\right.$, $t_{f}$ 了に和りる状態罢と制御㫪を表す。本論文で提案す る計算アルゴリズムは，終端值 $x\left(t_{f}\right)$ に拘束がある場 合に娄適用できるが，第 3 章，第 4 章でのアルゴリズ ムの説明では表現を簡単にするため，終端値 $x\left(t_{f}\right)$ は 上りあえず自由として扰く。終端に拘束加与えられた 場合の解法は筑 5 章の計算例で述べる。

\section{3. 不動点定理の適用}

最遍制御理論でよく知られているように(4)，ラグラ ンジ二乗数 $\lambda(t) \in R^{n}$ を導入すると，第 2 章の最小化 問題の解である $x^{\mathrm{opt}}(t), u^{\mathrm{opt}}(t)$ について，最小性の必 要条件加次の式を得る(付録 1)。

$$
\begin{aligned}
\dot{\lambda}(t)= & -A^{T}(t) \lambda(t)-Q(t) x^{\mathrm{opt}}(t) \\
& -g_{x}^{T}\left(x^{\mathrm{oPt}}(t)\right) \lambda(t)-q x^{T}\left(x^{\mathrm{opt}}(t)\right) \\
\lambda\left(t_{f}\right)= & Q_{f} x^{\mathrm{opt}}\left(t_{f}\right) \ldots \ldots \ldots \ldots \ldots \ldots \ldots \ldots \\
u^{\mathrm{opt}}(t) & =-R^{-1}(t) B^{T}(t) \lambda(t) \ldots \ldots \ldots \ldots \ldots
\end{aligned}
$$

以後，表現定簡単にするため $x^{\mathrm{opt}}(t), u^{\mathrm{opt}}(t)$ を， $x(t), u(t)$ で老す。

$(1),(3),(4)$ 式をいっしょにすると, $x(t), \lambda(t)$ についての非線形連立微分方程式

$$
\left.\begin{array}{rl}
\dot{x}(t)= & A(t) x(t)-B(t) R^{-1}(t) \\
& \cdot B^{T}(t) \lambda(t)+g(x(t)) \\
x\left(t_{i}\right)= & x_{i} \\
\dot{\lambda}(t)= & -A^{T}(t) \lambda(t)-Q(t) x(t) \\
& -g_{x}{ }^{T}(x(t)) \lambda(t)-q_{x}{ }^{T}(x(t)) \\
\lambda\left(t_{f}\right)= & Q_{f} x\left(t_{f}\right)
\end{array}\right\} \ldots \ldots . .
$$

立得る。

すなわち，節 2 章の最小化問題が (5)，(6)式のご とく, xについては初期点で， スについては終端点で 境界条件が与光られる2 点境界儘間題に㷌着する。つ まり，(5)，(6)式の解 $x(t), \lambda(t)$ を求めれば $x(t)$, $u(t)=-R^{-1}(t) B^{T}(t) \lambda(t)$ は最小性の必要条件を满足す る。

ところで，(5)，(6)式は非線形方程式であり，線 形方程式しちがって，この2 点境界值問題を解くこと 敹加しい。

そのため, ベルマンは(5)，(6)式について二ュー トンラプソン・カントロビッチ法に基づく算線倾化法
によって解く方法を示している(1)が、ここでは少 し違った簡単なアルゴリズムを提案する。まず，表見 を簡単にするため。。

$$
\begin{aligned}
& Z(t)=\left(\begin{array}{l}
x(t) \\
\lambda(t)
\end{array}\right) \\
& F(t)=\left(\begin{array}{cc}
A(t) & -B(t) R^{-1}(t) B^{T}(t) \\
-Q(t) & -A^{T}(t)
\end{array}\right) \\
& G(Z(t))=\left(\begin{array}{l}
g(x(t)) \\
-g_{x}^{T}(x(t)) \lambda(t)-q_{x} T(x(t))
\end{array}\right)
\end{aligned}
$$

と枋く。

(5), (6) 式任

$$
\begin{aligned}
& \dot{Z}(t)=F(t) Z(t)+G(Z(t)) \\
& Z\left(t_{i}\right)=\left(\begin{array}{l}
x_{i} \\
\lambda\left(t_{i}\right)
\end{array}\right) \\
& Z\left(t_{f}\right)=\left(\begin{array}{l}
x\left(t_{f}\right) \\
Q_{f} x\left(t_{f}\right)
\end{array}\right)
\end{aligned}
$$

と表さ机る。ただし， $\lambda\left(t_{i}\right)$ は末知量。

いま仮りに，初期条件 $Z\left(t_{i}\right)$ か $Z\left(t_{i}\right)=Z_{i}$ として与 えられたとする。ここで， $Z(t)$ の最初の推定解 $Z_{0}(t)$ を適当に与える。(例えば， $Z_{0}(t) \equiv Z_{i}$ とですすればよ $\left.\omega_{0}\right)$

次に方程式

$$
\dot{Z}_{1}(t)=F(t) \cdot Z_{1}(t)+G\left(Z_{0}(t)\right)
$$

を初期条件 $Z_{1}\left(t_{i}\right)=Z_{i}\left(=Z_{0}\left(t_{i}\right)\right)$ のも乙に解けば, 次 の推定解 $Z_{1}(t)$ を得る。この $Z_{1}(t)$ を用いて方程式

$$
\dot{Z}_{2}(t)=F(t) \cdot Z_{2}(t)+G\left(Z_{1}(t)\right)
$$

を(8)式と同一の初期条件 $Z_{2}\left(t_{i}\right)=Z_{i}$ を用いて解け ば更に次の推定解 $Z_{2}(t)$ を得る。同様の操作を次々に 繰り返して, 方程式

$$
\dot{Z}_{k}(t)=F(t) \cdot Z_{k}(t)+G\left(Z_{k-1}(t)\right)
$$

を同一の初期条件 $Z_{i}=Z_{0}\left(t_{i}\right)=Z_{1}\left(t_{i}\right)=\cdots=Z_{k}\left(t_{i}\right)=\cdots$ の屯とに解くと，推定解の関数列 $\left(Z_{k}(t)\right)$ が得られる。 次にこのアルゴリズムによって得られる推定解の関数 列 $\left(Z_{k}(t)\right)$ 加漸近的に収束することを不動点定理を用 いて証明する。

まず用語の定艇

定義 $1 E$ を距離空間, $\tilde{T}$ を $E$ から $E$ への写像 とする。ある正数 $\varepsilon<1$ が存在して $E$ の任意 の 2 点 $x, y$ に対して不等式 $d(\tilde{T}(x), \tilde{T}(y))$ $\leqslant \varepsilon d(x, y)$ が成り立つとき $\widetilde{T}$ は樎小写像で ある。

定義 2 写像 $\tilde{T}$ に対して $\tilde{T}(a)=a$ なる点 $a$ を $\tilde{T}$ の不䡃点という。

定理 完備距嚾空間 $E$ から $E$ への写像 $\widetilde{T}$ について $\tilde{T}$ のある幕 $\tilde{T}^{p}=\underbrace{\tilde{T} \circ \tilde{T} \circ \tilde{T} \circ \cdots \circ \tilde{T}}_{p \text { 個 }}$ が縮小写像であると 
$\nexists$

(i) $\tilde{T}$ はただ一つの不動点 $a$ を持つ。

(ii) $x_{0}$ を $E$ 在意の元として $\left\{x_{k}\right\}$ が次式に上 って与えられたとする。

$$
x_{k}=\tilde{T}_{x_{k-1}}(k=1,2, \cdots)
$$

このとき $\left\{x_{k}\right\}$ 仗収束し $\lim _{k \rightarrow \infty} x_{k}=a$ である。

上記の定理空区間 $\left(t_{i}, t_{f}\right)$ 加ら $R^{2 n}$ 八の連続関数 全体の集合 $C\left[t_{i}, t_{f}\right]$ に適用する。C $\left(t_{i}, t_{f}\right)$ がノル

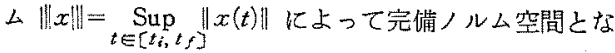

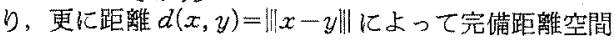
となるこしは周知の通りである。次に方程式 (9)は線 形方程式である加ら，よく知られた線形方程式の理 墖(4)- 6 亿占り

$$
Z_{k}(t)=\Phi\left(t, t_{i}\right) Z_{i}+\int_{t_{i}}^{t} \Phi(t, \tau) G\left(Z_{k-1}(\tau)\right) d \tau
$$

ここに $\Phi\left(t, t_{i}\right)$ は䙲移行列上呼ばれ，次の微分方程式 の解である。

$$
\begin{aligned}
& \frac{d}{d t} \Phi\left(t, t_{i}\right)=F(t) \Phi\left(t, t_{i}\right) \\
& \Phi\left(t_{i}, t_{k}\right)=I_{2 n}
\end{aligned}
$$

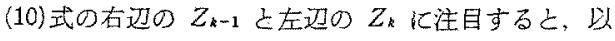
下の上うに $C\left(t_{i}, t_{s}\right)$ 加ら $C\left[t_{i}, t_{f}\right]$ への写像 $\tilde{T}$ が 定義される。

$$
\begin{aligned}
& Z \in C\left(t_{i}, t_{f}\right], \quad \widetilde{T}(Z) \in C\left(t_{i}, t_{f}\right\} \\
& \widetilde{T}(Z)(t)=\Phi\left(t, t_{i}\right) Z_{i}+\int_{t_{i}}^{t} \Phi(t, \tau) G(Z(\tau)) d \tau
\end{aligned}
$$

以下の議論では $\tilde{T}$ のある要が自己縮小写像となるこ 亡をいう。

ここで $G(Z)$ は $Z$ に開してリプシッツ連続とする。 すなわち，ある $L>0$ が存在して任意の $\omega, \omega^{\prime} \in R^{2 n}$ について,

$$
\left\|G(\omega)-G\left(\omega^{\prime}\right)\right\| \leqslant L\left\|\omega-\omega^{\prime}\right\|
$$

が成り立つものよする。

$$
\text { そこで, } \operatorname{Sup}_{t, \tau \in\left[t_{i, t}\right]}\|\Phi(t, \tau)\|=K
$$

とおけば評価式

$$
\begin{aligned}
& \left\|\tilde{T}\left(Z_{1}\right)(t)-\tilde{T}\left(Z_{0}\right)(t)\right\| \\
& =\left\|Z_{2}(t)-Z_{1}(t)\right\|=\| \int_{t_{i}}^{t} \Phi(t, \tau)\left\{G\left(Z_{1}(\tau)\right)\right. \\
& \left.\quad-G\left(Z_{0}(\tau)\right)\right\} d \tau \| \\
& \quad \leqslant K \cdot L \int_{t_{i}}^{t}\left\|Z_{1}(\tau)-Z_{0}(\tau)\right\| d \tau \\
& \quad \leqslant K \cdot L\left\|Z_{1}-Z_{0}\right\| \int_{t_{i}}^{t} d \tau \\
& =K \cdot L \cdot\left(t-t_{i}\right)\left\|Z_{1}-Z_{0}\right\|
\end{aligned}
$$

が得られる。ただし。

$$
\left\|Z_{1}-Z_{0}\right\|=\operatorname{Sup}_{t \in\left[t_{i}, t_{f}\right]}\left\|Z_{\mathrm{l}}(t)-Z_{0}(t)\right\|
$$

次に上の式在用いて

$$
\begin{aligned}
& \left\|\tilde{T}^{2}\left(Z_{1}\right)(t)-\tilde{T}^{2}\left(Z_{0}\right)(t)\right\| \\
& =\left\|Z_{3}(t)-Z_{2}(t)\right\|=\| \int_{t_{i}}^{t} \Phi(t, \tau)\left\{G\left(Z_{2}(\tau)\right)\right. \\
& \left.\quad-G\left(Z_{1}(\tau)\right)\right\} d \tau \| \\
& \quad \leqslant K \cdot L \cdot \int_{t_{i}}^{t}\left\|Z_{2}(\tau)-Z_{1}(\tau)\right\| d \tau \\
& \quad \leqslant K^{2} \cdot L^{2} \cdot\left\|Z_{1}-Z_{0}\right\| \int_{t_{i}}^{t}\left(\tau-t_{i}\right) d \tau \\
& =K^{2} \cdot L^{2} \cdot \frac{\left(t-t_{i}\right)^{2}}{2 !} \cdot\left\|Z_{1}-Z_{0}\right\|
\end{aligned}
$$

を得る。

更に同様の操作を次々に繰り返して

$$
\begin{aligned}
& \left\|\tilde{T}^{k}\left(Z_{1}\right)(t)-\tilde{T}^{k}\left(Z_{0}\right)(t)\right\| \\
& =\left\|Z_{k+1}(t)-Z_{k}(t)\right\| \\
& \quad \leqslant K \cdot L \cdot \int_{t_{i}}^{t}\left\|Z_{k}(\tau) \cdot Z_{k-1}(\tau)\right\| d \tau \\
& \quad \leqslant K^{k} \cdot L^{k} \cdot\left\|Z_{1}-Z_{0}\right\| \int_{t_{i}}^{t} \frac{\left(\tau-t_{i}\right)^{k-1}}{(k-1) !} d \tau \\
& =K^{k} \cdot L^{k} \cdot \frac{\left(t-t_{i}\right)^{k}}{k !}\left\|Z_{1}-Z_{0}\right\|
\end{aligned}
$$

が得ら机る。従って

$$
\left\|\tilde{T}^{k}\left(Z_{1}\right)-\tilde{T}^{k}\left(Z_{0}\right)\right\| \leqslant K^{k} \cdot L^{k} \frac{\left(t_{f}-t_{i}\right)^{k}}{k !}\left\|Z_{1}-Z_{0}\right\|
$$

でする。この評価式は $k$ が十分大きくなれば，

$$
K^{k} \cdot L^{k} \frac{\left(t_{s}-t_{i}\right)^{k}}{k !}<1
$$

となり $\widetilde{T}^{\star}$ 加目己縮小写像亡なることを示している。 よって前述の不勳点定理によって $\widetilde{T}$ は唯一の不動点 老持ち，関数列 $\left\{Z_{k}\right\}$ 加その不動点（関数）に一様収 束する。よって(11)式などの仮定のもとに上述の繰り 返し計算アルゴリズムによって得られる関数列 $\left(Z_{k}\right)$ の収束性が不動点定理に上り証明された。その極限関 数 $Z \infty(t)$ は (7) 式の初期条件 $Z \infty 0\left(t_{i}\right)=Z_{i}$ の解であ る。つまり (5)，(6)式の非線形 2 点境界䍜問題の解 $x(t), \lambda(t)\left(Z \infty(t)=\left(\begin{array}{l}x(t) \\ \lambda(t)\end{array}\right)\right)$ が求められる。これらの $x(t), \lambda(t),\left(u(t)=-R(t)^{-1} B(t)^{T} \lambda(t)\right)$ は前述の通り最小 性の必要条件を满たしている。

よころが $Z_{i}=\left(\begin{array}{l}x\left(t_{i}\right) \\ \lambda\left(t_{i}\right)\end{array}\right)$ において $x\left(t_{i}\right)$ は指定されて

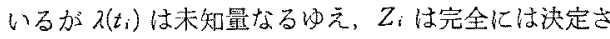
れていない。しかし，各kについて，方程式(9)は， $Z_{k}(t)$ に関する線形方程式であるから，この2 点境界 值問題を解くことは極的て容易である。 奏際 $Z_{k}(t)=\left(\begin{array}{l}x_{k}(t) \\ \lambda_{k}(t)\end{array}\right)$ にいて, 従来知られているリ カッチ変魥 


$$
\lambda_{k}(t)=S_{k}(t) x_{k}(t)+h_{k}(t)
$$

を導入し，との式と(9)式から次のリカッチ方程式と 補助方程式

$$
\begin{aligned}
\dot{S}_{k}(t)= & -Q(t)-A^{T}(t) S_{k}(t)-S_{k}(t) A(t) \\
& +S_{k}(t) B(t) R^{-1}(t) B^{T}(t) S_{k}(t) \ldots(12) \\
\dot{h}_{k}(t)= & -A^{T}(t) h_{k}(t)+S_{k}(t) B(t) R^{-1}(t) \\
& \cdot B^{T}(t) h_{k}(t)-S_{k}(t) g\left(x_{k-1}(t)\right) \\
& -q_{x}^{T}\left(x_{k-1}(t)\right)-g_{x}^{T}\left(x_{k-1}(t)\right) \lambda_{k-1}(t)
\end{aligned}
$$

を得る (付録 2 )。乙こで $S_{k}(t)$ は $n \times n$ 行列, $h_{k}(t)$ は $n$ 次ベクトルである。しかむ(12)，(13)式の境界条 件は終端条件

$$
\begin{aligned}
& S_{k}\left(t_{f}\right)=Q_{f} \\
& h_{k}\left(t_{f}\right)=0 . .
\end{aligned}
$$

として完全汇決定さ机る。

ここで (12)，(13) 式を終端条件 (12)'，(13)'儿従って ts から $t_{i}$ まで逆方向传樻分すれね゙， $S_{k}\left(t_{i}\right), h_{k}\left(t_{i}\right)$ を 得ることができ

$$
\lambda_{k}\left(t_{i}\right)=S_{k}\left(t_{i}\right) x_{k}\left(t_{i}\right)+h_{k}\left(t_{i}\right)
$$

により $\lambda_{k}\left(t_{i}\right)$ が決定される。

すなわ古， $Z_{k}\left(t_{i}\right)=\left(\begin{array}{l}x_{k}\left(t_{i}\right) \\ \lambda_{k}\left(t_{i}\right)\end{array}\right)$ が決まり $(9)$ 式は初期 値問題核置換される。

(5)，(6)式あるいは，(7)式の非線形 2 点境界值問 題を直接解〈かかりに，(9)式の線形 2 点境界檤問題 を繰り返し解けば，その解は(5)，(6)式古るいは(7) 式の解汇澌次近づき，它の極限解 $x \infty(t), \lambda \infty(t)(u \infty$ $\left.(t)=-R(t)^{-1} B^{T}(t) 200(t)\right)$ は最道性の必要条件を満足 する。ただし，これらの極限解は実際の数值計算では 連続形を離散形におきかえたり，計算機の有限けたに よる計算䛊差などのたる，正磪な最適解ではなくその 近似解である。

また，線形 2 点境界值問題に対しては，終端点等式 拘束などの境界条件の問題す解くことができる。例元

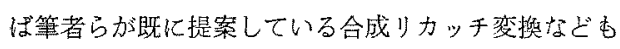
適用できる。こ饥については第 5 章の計算例で述べる ととにする。

次に本法の特微について述べる。ニートンラプン ン法に基づくベルマンの準線形化法(1)(12) 歨例化とっ て比校してみる。

この方法は(11)式について準線形化を行い，渐化式

$$
\begin{aligned}
\dot{Z}_{k}= & \left\{F Z_{k-1}+G\left(Z_{k-1}\right)\right\} \\
& +\left.\frac{\partial}{\partial w}\{F w+G(w)\}\right|_{w=Z_{k-1}} \cdot\left(Z_{k}-Z_{k-1}\right) \\
= & \left\{F+G z\left(Z_{k-1}\right)\right\} Z_{k} \\
& +\left\{G\left(Z_{k-1}\right)-G z\left(Z_{k-1}\right) Z_{k-1}\right\}
\end{aligned}
$$

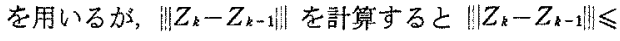
$\tilde{M}^{2}\|\| Z_{1}-\left.Z_{0}^{0}\right|^{2 k}$ 上なる(12)。乙てで $\tilde{M}>0$ は $\left|t_{f}-t_{i}\right|$, $\|F\|,\left\|G\left(Z_{k-1}\right)\right\|,\left\|G z\left(Z_{k-1}\right)\right\|,\left\|G z z\left(Z_{k-1}\right)\right\|$ によって定め られる。

この評洒式は $\tilde{M}\left\|Z_{1}-Z 0_{0}\right\|<1$ が成立するように，

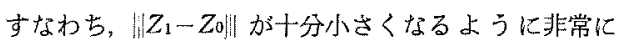
うまく最初の推定解を与元机ば 2 次収束することを示 している。こ机は局所収束性といわ机る゙，このよう な推定解の選択は難かしいととが多い。このためとの ように「感度のよい」方法を数値計算で実行した場合, 発生する過大な修正量のために収束が得られずに， オーバフローを起とすことがしばしば起きる。本方法 では $\left\|Z_{*}-Z_{k-1}\right\| \leqslant \frac{\tilde{M}^{k}}{k !} \cdot\left\|Z_{1}-Z_{0}\right\|(た た ゙ し ， \tilde{M}=K \cdot L$. $\left.\left|t_{f}-t_{i}\right|\right)$ であり $k$ が十分大きければ， $G(Z) の Z$ に

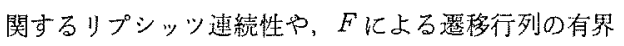
性などの条件を必要とするが，\|I $Z_{1}-Z$ O は無関係化収束が期待できる。すなわち， $\tilde{M} / Z_{1}$ Z 0\|\| 1 である必要はない。更にアルゴリズムの渐近 的な性翼からみて，1回1回の繰り返し訪算ではそ机 ほど大きくない修正量が発生すると考えら机る。ま た，大域的な収束性を保障し得るアルゴリズムとして こう配法などがあるが，てれらはあるバラメータの試 行的選択が必要である。例えば，こう配法では $J\left(u_{k}\right.$ $\left.+\alpha H_{u}\left(u_{k}\right)\right\rangle$ が最小上なる上うに $\alpha>0$ 甞避ばなくては ならない(13)。その他, 準ニュートン法に基ついたアル ゴリズム ${ }^{(13)}$ 屯るるが，そ机は計算法が煩雑で多くのメ モリーを必要とする(13)。本諭文の方法はこのような パラメータの選択を必要とせず，各ステップでとのメ モリーは $x_{k}, \lambda_{k}$ だけですみ計算法笛簡単である。要 するにとの方法の特徴は適当な初期解から始め計算回 数任多少多くなるが，パラメータの選択を必要とせず に取束を得ることができ,メモリ一あそ机はど多く必 要としない簡単な計算法である。

しかしながら，このような特徽があっても，実際の 数值計算では $\tilde{M}\left\|Z_{1}-Z_{0}\right\|$ が火き過ぎる上なかなか 収束が得られないとと屯あり得る。そてで $\tilde{M} \| Z_{1}$ Z はない。）なるように土夫するととるすべきである。 そこで一つの土夫として,$\dot{x}=A x+B u+g(x)$ による $x$ について非線形項 $g(x)$ と $q(x)$ を $\bar{x}$ 亿無関係な時 変形定数として扱い，線形システム

$$
\begin{aligned}
& \dot{\tilde{x}}(t)=A(t) \tilde{x}(t)+B(t) \tilde{u}(t)+g(x) \\
& \tilde{x}\left(t_{0}\right)=x_{i} \\
& J=\int_{t_{i}}^{t_{f}}\left\{\frac{1}{2} \tilde{x}(t)^{T} Q(t) \tilde{x}(t)+\frac{1}{2} \tilde{u}(t)^{T} R(t) \tilde{u}(t)\right.
\end{aligned}
$$




$$
+q(x)\} d t+\frac{1}{2} \tilde{x}^{T}\left(t_{s}\right) Q_{j} \tilde{x}\left(t_{s}\right)
$$

の最適解 $x_{0}$ を求好これを最初の推定解とする方法が 考元られる。

この方法を任意の $k$ に適用してシステム

$$
\begin{aligned}
& \left.\dot{x}_{k}(t)=A(t) x_{k}(t)+B(t) u_{k}(t)+g\left(x_{k-1}(t)\right)\right\} \\
& x_{k}\left(t_{j}\right)=x_{i} \\
& J=\int_{t_{j}}^{t f}\left\{\frac{1}{2} x_{k}{ }^{T}(t) Q(t) x_{k}(t)+\frac{1}{2} u_{k}^{T}(t) R(t) u_{k}(t)\right. \\
& \left.\quad+q\left(x_{k-1}(t)\right)\right\} d t+\frac{1}{2} x_{k}^{T}\left(t_{f}\right) Q_{f} x_{k}\left(t_{f}\right)
\end{aligned}
$$

の最適化安繰り返す方法については筆者らは既に提案 している ${ }^{(9)}$ 。太芯し，乙の方法は $g_{x}=0 ， q_{x}=0$ (付録 2)とするためその収束解が最適性の必要条件をみたす というととは，(3)式圭用いることができずいまの上 ころ明らかでない。

なお，乙の方法による収束解の存在については，山 本，杉浦氏 ${ }^{(8)}$ らの結果尼用いて政明するととができ る。第 4 章のアルゴリズムではこのような工夫につい て述心る。

\section{4. アルゴリズム}

凶下に第3章で述べた繰り返し計算法を若干の工夫 を入れ，アルゴリズムとして定式化する。

Step $0\left(Z_{0}(t)=\left(\begin{array}{l}x_{0}(t) \\ \lambda_{0}(t)\end{array}\right)\right.$ 与える

$u(t)$ に適当な推定解 $u_{0}(t)$ を与え，方程式(1)定初 期条件 $x\left(t_{i}\right)=x_{i}$ の古と飞解く。

このときの解を $x_{0}(t)$ とし $\lambda(t)$ に適当な推定解 $\lambda_{0}(t)$ を与える。例えば， $\lambda_{0}(t) \equiv Q_{s} x\left(t_{f}\right)$ とすれば上い。

また，このよきの評価関数の $J$ 值を(2)式により

計算し， $J_{0}$ と护き $J_{1}^{(0)}=J_{0}, k=1$ とする。

Step $1\left(S_{k}, h * \text { O評算 }\right)^{* 1}$

$x_{0}(t) ， \lambda_{0}(t)$ により，方程式(12)，(13)在䅂端条件 $(12)^{\prime}$ ，(13)'のむとに解き， $S_{1}\left(t_{i}\right), h_{1}\left(t_{i}\right)$ を求好る。

Step $2\left(Z_{k}\left(t_{i}\right)\right.$ の決定 $Z_{k}(t)=\left(\begin{array}{c}x_{k}(t) \\ \lambda_{k}(t)\end{array}\right)$ の諳算 $)$

$\lambda_{1}\left(t_{i}\right)=S_{1}\left(t_{i}\right) x_{i}+h_{1}\left(t_{i}\right)$ Kより $\lambda_{1}\left(t_{i}\right)$ を求的る。

万程式 (9)を解き（このときの $x$ 在 $x_{1}$ とする。） $u_{1}(t)=-B(t) R^{-1}(t) B^{T}(t) \lambda_{1}(t)$ により $u_{1}(t)$ を求好 ${ }^{\circ}$ このときの評価関数 $J$ の值老 $J_{1}^{(k)}$ 亡扔く。

Step $3\left(Z_{k}(t)\right.$ の $J^{(k)}$ による収来のチェック)

(i) 十分小さな $\varepsilon>0$ に対して $\left|J_{1}^{(k-1)}-J_{1}^{(k)}\right|<$ $\varepsilon$ が成立する場合 $\left|J_{1}^{(k)}-J_{0}\right|<\varepsilon$ が成立す机弪匴を

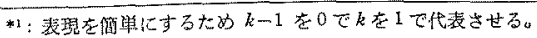

電学論 C, 107 巻 12 号, 昭 62
德此する。そうでるければ，

$u_{0}(t)=u(t)$

$\lambda_{0}(t)=\lambda_{1}(t)$

Łして Step 0 に香どる。

(ii)（i 加成立しない場合

$x_{0}(t)=x_{1}(t)$

$\lambda_{0}(t)=\lambda_{1}(t)$

$k=k+1$

として Step 1 ともどる。

Step 0〜Step 3 ば解が収束するまで十分な回数を 繰り返す必要があるが，(12)式の $S_{k}(t)$ の程式は終 端条件方 $S_{k}\left(t_{f}\right)=Q_{f}$ であり，その係数 $A(t), B(t)$, $Q(t), R(t)$ 繰り返しによって变化しないから 1 回解 くだけでよい。すねわち，S $S_{1}(t)$ だけを求め机ばよい。 また，䅣分は数值皘分を行う加ら，Step 1 Step 3 の繰り返しを行って屯，誤差か湦積されるととがあり $Z_{k}(t)$ 加取束しても $u_{0}(t)=u_{1}(t)$ として Step 0 に民し

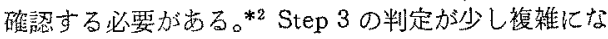
っているのはそのためである。また, Step 0と Step 1 Step 2 の实行の過程で $x_{0}$ と $x_{1}$ が大をく隔たる 場合はオ一バフローが発生するかもしれない。特に について終端拘束（㣪述）か与えられた場合，最初の x。の与え方が不通当であるときなどはオーバフロー が発生しやすくなる。乙の場合 $g_{x}$ や $q_{x}$ の項の影 響が䑲視できない恬ど大きくなる。そこで必要に応 じて第了獐述心゙たように $g_{x}=0, q_{x}=0$ とする方 法 ${ }^{(8)(9)}$ を併用する。す坊方，最小化問題(14)，(15) 式を解くアルゴリズムを併用する。具体的纪次のよう な土夫它行う。

(a) 最初の Step 0〜Step 3 の寒行では $g_{x}=0$, $q_{x}=0$ とする。

(b) Step $3 の$ (i)の判定の前に適当な大きさの $M>0$ について $\| x_{1}-x$ 顺 $<M$ 加成立するから゙うかを 判定し，成立しない場合 $g_{x}=0, q_{x}=0$ として Step 0 によ゙る。

实用的には $\left\|\left|x_{1}-x_{0}\right|\right\|$ の代りに $\left|J_{1}^{(k)}-J_{0}\right|$ を用い る方が簡筧である。いずれにしてす $M$ の大きさはい まのとこる陚行的㳄決めざを得ない。

\section{5. 計 算 例}

以上のアルゴリズムをシステムの方程式がVan der pole の非線形方程式で与えられ，評溉閣数が 2 次形 式で与えられる次の最小間題について，(i)笗端点が

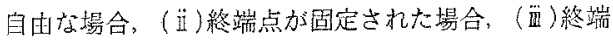

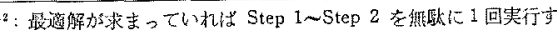
ること江方汃 Step 3 の判定で計算络停止する。 
点に等式拘束が与えられた場合の三つの場合について 邀用してみた。

$$
\begin{array}{ll}
\dot{x}_{1}=x_{2} & x_{1}(0)=1 \\
\dot{x}_{2}=-x_{1}+\left(1-x_{1}^{2}\right) x_{2}+u & x_{2}(0)=0 \\
J=\int_{0}^{5} \frac{1}{2}\left(x_{1}^{2}+x_{2}^{2}+u^{2}\right) d t &
\end{array}
$$

ただし，你数などは次のようにおいた。

$$
\begin{array}{ll}
A(t)=\left(\begin{array}{rr}
0 & 1 \\
-1 & 1
\end{array}\right) & g(x)=\left(\begin{array}{cc}
0 & \\
-x_{1}^{2} & x_{2}
\end{array}\right) \\
B(t)=\left(\begin{array}{l}
0 \\
1
\end{array}\right) & Q(t)=\left(\begin{array}{ll}
1 & 0 \\
0 & 1
\end{array}\right) \\
R(t)=1 &
\end{array}
$$

また，以下の説明で繰り返し回数とは Step 0 Step 3 の 2 重のループのうち, 内側のループの実行回数の総 数を示し, 最初の推定解は $u_{0}(t) \equiv 0, \lambda_{0}(t) \equiv 0$ とした。

(i) 釉端点が自由な埸合 第 2 章〜第 4 章で説

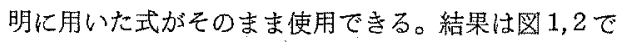
示す通りである。繰り返し回数 27 回で $J=1.479$ を得 た。Nedeljkovic ${ }^{\prime 3)}$ の結果と比较すると十分近似にな つている屯のと考えられる。また，乙の場合第 4 章で

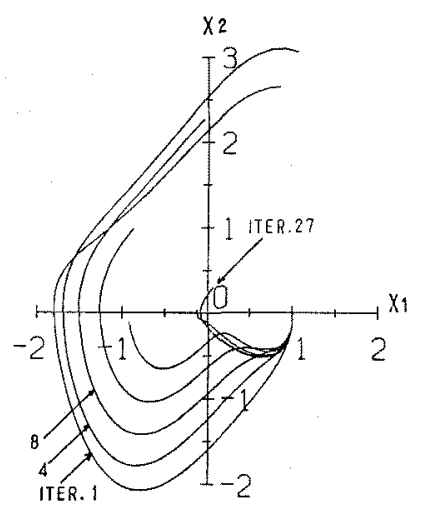

因 1 解軌道(終端自由の場合)

Fig. 1. Trajectories by this method (terminal free).

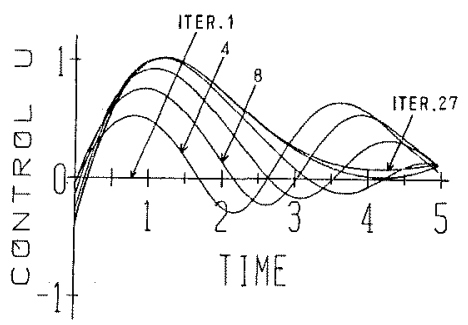

図 2 制御の収束 (終端自由の場合)

Fig. 2. Convergence of Control Function (terminal free).
述べたような $g_{x}=0$ とする工夫は必要としなかった。

(ii) 終端点が固定された場合, 例では

$$
\begin{aligned}
& x_{1}(5)=0 \\
& x_{2}(5)=0
\end{aligned}
$$

とする。一般に樂端点が $x\left(t_{s}\right)=x$ ，の形で固定され ている場合 $(6)$ 式の $\lambda(t)$ 飞関する钱分方程式の境界 条件は $\lambda\left(t_{i}\right), \lambda\left(t_{f}\right)$ とも末知である。そてで逆りカッ 于喵換 ${ }^{(10)} x_{k}(t)=S_{k}(t) \lambda_{k}(t)+h_{k}(t)$ を用いることにす る。乙の場合 (12), (13) 式に相当する式估

$$
\begin{aligned}
\dot{S}_{k}(t)= & A(t) S_{k}(t)+S_{k}(t) A^{T}(t)-B(t) R(t) B^{T}(t) \\
& +S_{k}(t) Q(t) S_{k}(t) \\
S_{k}\left(t_{f}\right)= & 0 \\
\dot{h}_{k}(t)= & \left\{A(t)+S_{k}(t) Q(t)\right\} h_{k}(t)+g\left(x_{k-1}(t)\right) \\
& +S_{k}(t) g_{x}^{T}\left(x_{k-1}(t)\right) \lambda_{k-1}(t) \\
& +S_{k}(t) q_{x}^{T}\left(x_{k-1}(t)\right) \\
h_{k}\left(t_{f}\right)= & x\left(t_{f}\right)
\end{aligned}
$$

となる。計算結果は図 3，4の通りである。繰り返し

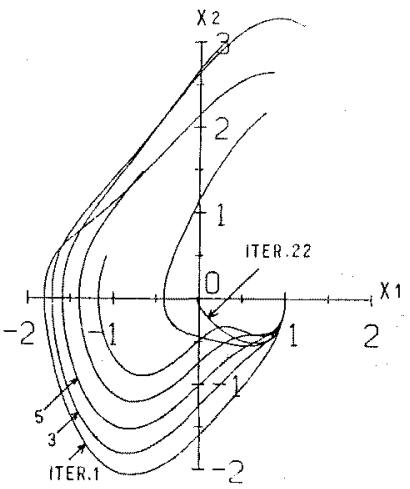

図 3 解軦道（終端固定の場合）

Fig. 3. Trajectories by this method (terminal fixed).

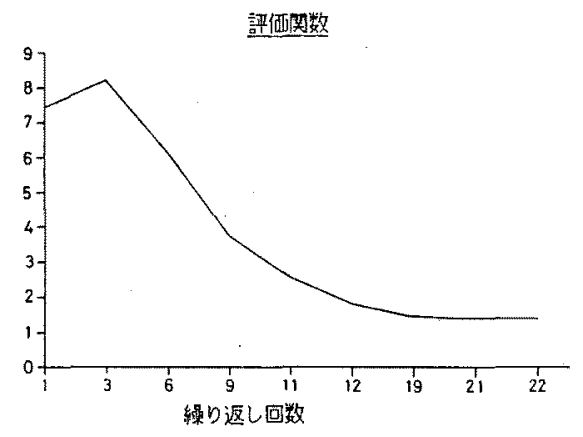

図 4 評価関数の収束（終端固定の場合）

Fig. 4. Convergence of Cost Function (terminal fixed). 
回数 22 回で $J=1.44, x_{1}(5)=-0.01, x_{2}(5)=-0.01$ を得た。また第 4 章で述心たように $g_{x}=0$ とする工 夫老用いている。ただし， $g_{x}=0$ とおいたのは繰り返 し1回から4回の間である。

(iii) 終端に等式拘束が与えられた場合，例では $-1-x_{1}(5)+x_{2}(5)=0$

とする。一般に蔠端住等式拘束

$$
\begin{aligned}
& D \cdot x\left(t_{s}\right)+E=0 \\
& D \in R^{s \times n} \\
& E \in R^{s}
\end{aligned}
$$

ただし， $\operatorname{rank}(D)=s(1 \leqslant s \leqslant n)$ が与えられた堭合, ベクトル $x(t)$ の要素の㮌序を適当に入れ替えるとと により

$$
\begin{aligned}
& \left(D_{1} \mid D_{2}\right)\left[\begin{array}{l}
x_{1} \\
x_{2}
\end{array}\right]+E=0 \\
& D_{1} \in R^{s \times s} \quad \operatorname{rank}\left(D_{1}\right)=s \\
& D_{2} \in R^{s \times(n-s)} \\
& x_{1} \in R^{s} \\
& x_{2} \in R^{n-s}
\end{aligned}
$$

と書き直すとよがでさる。そとで $x$ に対応して

$$
g(x), \lambda(t), Q(t), A(t), B(t), R(t), q(x)
$$

の要素の䐓序を入れ替え

$$
\left(\begin{array}{l}
x_{1}(t) \\
\lambda_{2}(t)
\end{array}\right)=\left(\begin{array}{ll}
S_{1}(t) & S_{2}(t) \\
S_{3}(t) & S_{4}(t)
\end{array}\right)\left(\begin{array}{l}
x_{2}(t) \\
\lambda_{1}^{\prime}(t)
\end{array}\right)+\left(\begin{array}{l}
h_{1}(t) \\
h_{2}(t)
\end{array}\right)
$$

とおくと(12)，(13)式㑑当する式孝尊くことができ

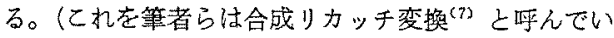
る。) 結果は図 5，6に示す通りである。繰り返し 17 回目で $J=1.769$

$$
-1-x_{1}(5)+x_{2}(5)=0.0951
$$

老得た。

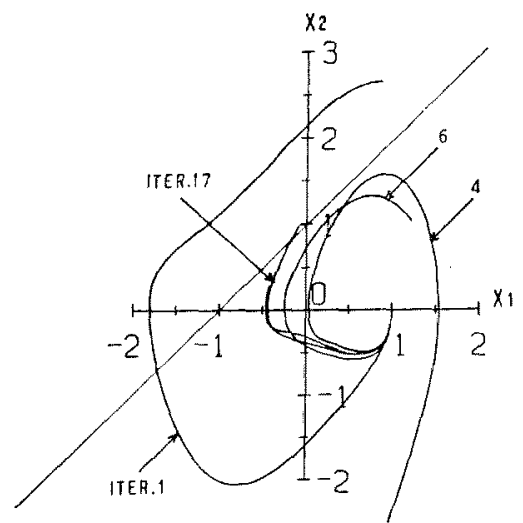

図 5 解軌道（終端等式拘束の場合）

Fig. 5. Trajectories by this method (terminal equality constrained).

電学論 $C, 107$ 巻 12 号, 昭 62

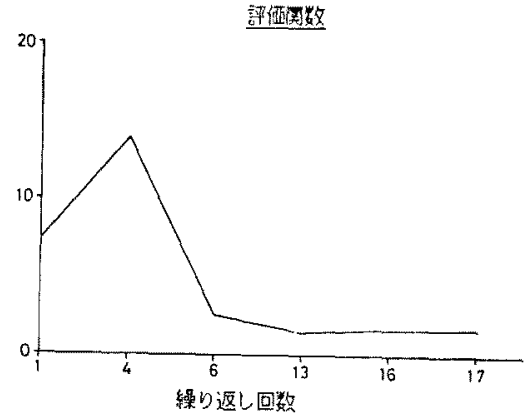

困 6 評価関数の取束（終端等式拘束の場合）

Fig. 6. Convergence of Cost Function (terminal equality constrained).

(ii)之同様 $g_{x}=0$ とする工夫を用いているがその 必要があったのは1回から5回の間であり，それ以後 は $g_{x}=0$ よLていない。

この問題について準線形化法や第2 変分法を最初の 推定解索 $u_{0}(t) \equiv 0$ しして試みたが, 繰り返し 1 回目 からオーバフローが発生し(ク暲算が続けられなくなっ た。

\section{6. あとがき}

本研究では，不動点定理を用いて解它漸近的に求好 る万法态試みた。この方法は収束の速さや解の精度の 点ではニュートン法偟るものと此較すると发るすの の，アルゴリズムが著しく簡単であり，計算の過程で オーバフローが発生しにくいため, 次数の高い問題に あ適応できると考えられる。

夷際の数值計算では，てのような此较的簡粹なアル ゴリズムによって近似解を求め，その近似解をもとに して，感度のよいアルゴリズムを適用するととが適当 と考える。

(昭和 62 年 2 月 24 日受付, 同 62 年 7 月 27 日再受付)

\section{文献}

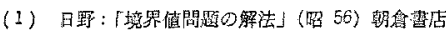

(2) D.H. Jacobson: "New Second-Order and First-Order Algorithms for Determing Optimal Control: Journal of Optimization Theory and Applications" 2, No. 6, 411 (1968)

(3) Nikola B. Nedeljkovic": "New Algorithms for Unconstrained Nonlinear Control Problems: IEEE Transactions on Automatic Control* AC-26. No. 4, 868 (1981)

(4) Donald M. Wiberg.: "Theory and Problems of State Space and Linear Systems" (1971) MeGraw.Hill

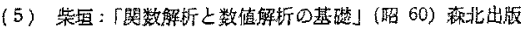

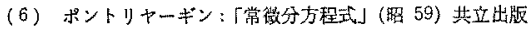

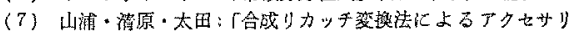

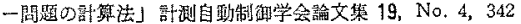


(吗 58)

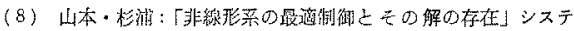
么之制御 16，9，737 (㽗 47)

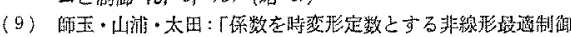

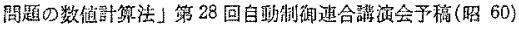

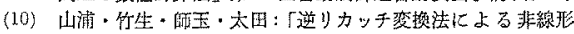

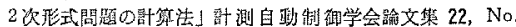
6,703 (嘫 61)

(11) シュヴフルツ: 解指学1

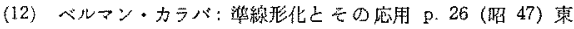
宗圆丵

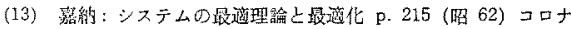
社

\section{付 録}

1. (1), (2)式加らハルトン関数を導入すると $H(x(t), u(t), \lambda(t))$

$$
\begin{aligned}
= & \frac{1}{2} x(t)^{T} Q(t) x(t)+\frac{1}{2} u(t)^{T} R(t) u(t)+q(x(t)) \\
& +\lambda^{T}(t)\{A(t) x(t)+B(t) u(t)+g(x(t))\}
\end{aligned}
$$

$\lambda(t):$ ラグランジニ乗数 $\in R^{n}$

鼠適制御理論加らよく知られているように，上の式 加ら $\lambda(t)$ にいての方程式が

$$
\begin{aligned}
\dot{\lambda}(t) & =-H_{x}{ }^{T} \\
& =-A^{T}(t) \lambda(t)-Q(t) x(t) \\
& -g_{x}{ }^{T}(x(t)) \lambda(t)-q_{x}{ }^{T}(x(t))
\end{aligned}
$$

で与えられる。特に $g_{x}^{T} や q_{x}^{T}$ の項が存在するとと に注意を要する。

$u(t)$ について早小性の必要条件

$$
\begin{aligned}
& H(x(t), u(t), \lambda(t))=\min _{v} H(x(t), v, \lambda(t)) \\
&\left(t \in\left(t_{i}, t_{f}\right)\right)
\end{aligned}
$$

加 $H_{u}=0$ として

$$
u(t)=-R^{-1}(t) B^{T}(t) \lambda(t)
$$

が得られる。
2. (9) 式を $Z_{k}(t)=\left(\begin{array}{l}x_{k}(t) \\ \lambda_{k}(t)\end{array}\right)$ と上って書き直すよ

$$
\begin{aligned}
\dot{x}_{k}(t)= & A(t) x_{k}(t)-B(t) R^{-1}(t) B(t)^{T} \lambda_{k}(t) \\
& +g\left(x_{k-1}(t)\right) \\
x_{k}\left(t_{i}\right)= & x_{i} \\
\dot{\lambda}_{k}(t)= & -A^{T}(t) \lambda_{k}(t)-Q(t) x_{k}(t) \\
& -g_{x}{ }^{T}\left(x_{k-1}(t)\right) \lambda_{k-1}(t)-q_{x^{T}}\left(x_{k-1}(t)\right) \\
\lambda_{k}\left(t_{f}\right)= & Q_{f} x_{k}\left(t_{f}\right)
\end{aligned}
$$

そてで $\lambda_{k}(t)=S_{k}(t) x_{k}(t)+h_{k}(t)$ と (5)'式から

$$
\begin{aligned}
\dot{\lambda}_{k}(t)= & \dot{S}_{k}(t) x_{k}(t)+S_{k}(t) \dot{x}_{k}(t)+\dot{h}_{k}(t) \\
= & \dot{S}_{k}(t) x_{k}(t)+S_{k}(t) A(t) x_{k}(t) \\
& -S_{k}(t) B(t) R^{-1}(t) B^{T}(t) S_{k}(t) x_{k}(t) \\
& -S_{k}(t) B(t) R^{-1}(t) B^{T}(t) h_{k}(t) \\
& +S_{k}(t) g\left(x_{k-1}(t)\right)+\dot{h}_{k}(t) \ldots \ldots \ldots(1
\end{aligned}
$$

また(6)式の右包加ら

$$
\begin{aligned}
\dot{\lambda}_{k}(t)= & -A^{T}(t) S_{k}(t) x_{k}(t)-A^{T}(t) h_{k}(t) \\
& -Q(t) x_{k}(t)-g x^{T}\left(x_{k-1}(t)\right) \lambda_{k-1}(t) \\
& -q_{x}{ }^{T}\left(x_{k-1}(t)\right) \ldots \ldots \ldots \ldots \ldots \ldots \ldots(15)
\end{aligned}
$$

$(14)^{\prime},(15)^{\prime}$ 式を $x_{k}(t)$ について整理することにより

$$
\begin{aligned}
\dot{S}_{k}(t)= & -Q(t)-A^{T}(t) S_{k}(t)-S_{k}(t) A(t) \\
& +S_{k}(t) B(t) R^{-1}(t) B^{T}(t) S_{k}(t)
\end{aligned}
$$

$\dot{h}_{k}(t)=-A^{T}(t) h_{k}(t)+S_{k}(t) B(t) R^{-1}(t) B^{T}(t) h_{k}(t)$

$-S_{k}(t) g\left(x_{k-1}(t)\right)-q_{x}{ }^{T}\left(x_{k-1}(t)\right)$

$-g_{x}{ }^{T}\left(x_{k-1}(t)\right) \cdot \lambda_{k-1}(t)$

を得る。また上式の境界条件は

$S_{k}\left(t_{f}\right) x_{k}\left(t_{f}\right)+h_{k}\left(t_{f}\right)=\lambda_{k}\left(t_{f}\right)=Q_{f} x_{k}\left(t_{f}\right)$

Lb

$S_{k}\left(t_{f}\right)=Q_{s}$

$h_{k}\left(t_{f}\right)=0$

として与えられる。 